\title{
O direito ao Ensino Fundamental em uma leitura dos resultados do IDEB e da política educacional em Curitiba-PR
}

Marilene Zampiri* Ângelo R. Souza**

\section{Resumo}

$\mathrm{O}$ artigo discute o papel do Estado na garantia do direito à educação a partir do cotejamento entre as ações governamentais e os resultados do IDEB das escolas públicas do Ensino Fundamental. Após apresentar as bases sobre as quais a análise teoricamente se sustenta, especialmente em Weber e Bourdieu, o trabalho apresenta e discute a (não) priorização ao Ensino Fundamental a partir dos dados do IDEB. As conclusões demonstram que a etapa do Ensino Fundamental (anos iniciais ou finais) que é priorizada pelo poder público tende a apresentar resultados mais homogêneos e ascendentes, significando, com isto, a ampliação do direito à educação. De outro lado, quando o poder público não prioriza dada parte do Ensino Fundamental, a heterogeneidade parece imperar, deixando os alunos que estão submetidos a esta condição mais dependentes de outras variáveis para ter o seu direito à educação garantido.

Palavras-chave: Direito à educação; Ensino Fundamental; Políticas Educacionais; IDEB.

\section{Introdução}

Este artigo discute o papel do Estado na disponibilização do direito à educação a partir do cotejamento entre as ações governamentais na área educacional e os resultados obtidos pelos estudantes em escolas mantidas pelo poder público. A análise está circunscrita às escolas que ofertam o Ensino Fundamental público na cidade de Curitiba.

Professora da Rede Municipal de Ensino de Curitiba-PR. Mestre em Educação pela UFPR.

E-mail: marizampiri@gmail.com

** Professor e pesquisador do Programa de Pós-Graduação em Educação e do Núcleo de Políticas Educacionais da UFPR. Doutor em Educação pela PUC-SP. E-mail: angelo@ufpr.br 
Parte-se do pressuposto que existe relação entre a aquisição escolar obtida por estudantes e a ação governamental como forma encontrada para materializar determinadas políticas educacionais. Esta relação, no entanto, não é linear nem absoluta, mas permite observar que as políticas educacionais, ou sua ausência, oportunizam e contribuem para o decrescimento do rendimento estudantil, portanto interferem de algum modo no direito à educação.

Este entendimento pressupõe que a ação governamental é tanto mais efetiva quanto maior for o número de beneficiados pelo direito à educação. Dado que o Ensino Fundamental é reconhecido como direito público e subjetivo ${ }^{l}$, ou seja, nenhum cidadão pode alienar-se ou ser alienado desse direito, o benefício deste bem social deve ser perspectivado para todos. Dessa forma, políticas educacionais, especialmente para o Ensino Fundamental, devem estar referenciadas pela distribuição equitativa desse benefício a todos. Assim, para esta etapa da Educação Básica, a efetividade da ação governamental deve ser mensurada pela possibilidade de tal direito atingir todos os cidadãos equitativamente.

Nesse aspecto, importa discutir o que se pode e deve aceitar como justo e adequado na modelagem conceitual do direito à educação, assim como os vários fatores que produzem o amálgama de onde derivam, tanto esta modelagem conceitual, como as políticas que orientam o sentido de sua implementação, as ações propostas para sua efetivação e, ao final, a ação executada no âmbito da organização social que é a escola. Mais precisamente, é preciso discutir o conceito, as intenções, as ações propostas e as ações executadas que configuram as políticas no âmbito dos sistemas educacionais com vistas à promoção do direito à educação.

O reconhecimento da educação como direito de $\operatorname{todos}^{2}$, tal como assegurado na legislação vigente e socialmente aceito, é resultado de processos de disputas travadas nos diferentes campos políticos. Assim, a normatização jurídica, a proposição de políticas que orientam o sentido da implementação do direito, as ações e prescrições potencialmente capazes de materializar políticas e a sua execução na escola, são campos políticos e, portanto, campos de luta e de disputa, que modelam o sentido do direito à educação em um dado momento histórico.

1 Art. 208, inciso VII, § $1^{\circ}$ da Constituição Federal de 1988.

2 Art. 205 da Constituição de 1988 
No campo do ordenamento jurídico, pode-se dizer que a educação sempre esteve presente nas discussões que pautaram os caminhos percorridos pelas constituições brasileiras, historicamente iniciadas com a Assembléia Nacional e Geral Constituinte em 1823 até a Constituição Cidadã de 1988. É possível perceber que no percurso das sucessivas edições da Carta Magna, a educação foi se constituindo ascendentemente como um direito, embora este movimento se mostre irregular, com avanços e retrocessos entre um processo constituinte e outro; irregularidade que decorre da disputa de poder que caracteriza tais espaços como campos políticos.

De acordo com a acepção de Bourdieu (2004), campo político pode ser entendido como um campo de luta e também um campo de forças, onde os que operam na política estão em permanente disputa pelo monopólio dos instrumentos de produção política. O monopólio dos meios de produção política conduz à acumulação de capital político, fator determinante para continuar a gerar produtos políticos que possibilitam continuar a operar em tal campo, o que equivale a permanecer no poder ou, pelo menos, dele participar. Tais produtos políticos (leis, políticas de implementação, ações e prescrições) são disponibilizados no mercado social para consumo da sociedade que, de acordo com o grau e o refinamento dos seus instrumentos de percepção e participação, os acolhe, passivamente ou não, com resistências ou não, como meio apropriado de satisfazer uma necessidade. Resulta daí que, quanto mais distantes estiverem os indivíduos da produção das políticas sociais, tanto maior a possibilidade de equívocos nas escolhas desses produtos.

O ordenamento do campo político atua como forma de dominação, na medida em que os produtos políticos daí provenientes são frutos de disputa legitimada por certa ordem, que ora constrange, ora impulsiona o processo de elaboração daqueles produtos políticos. $\mathrm{O}$ ordenamento tanto pode ser ativado para refrear forças que estão ganhando terreno no campo político, pondo em risco os que dominam o jogo, como pode ser acionado para permitir a participação de quem não estava no jogo.

Tome-se como exemplo a vinculação de recursos financeiros destinados à educação. O desenho e ordenação deste produto político são resultados da disputa travada por forças atuantes no campo político. Tal ordenação pode ser acionada em outro campo de disputa política tanto para constranger reivindicações não ordenadas mesmo que socialmente necessárias (por exemplo, aumento 
da vinculação orçamentária, dado existir outras demandas sociais igualmente importantes) como para garantir o cumprimento do estabelecido, mediante a divisão e participação no poder. Nessas disputas é comum a defesa ou reprovação de um ato ou de uma ação pelo argumento da constitucionalidade ou inconstitucionalidade. A maior parte dos ordenamentos da educação é disputada no campo político, o qual se constitui em campo de disputa e em disputa.

Assim, diferentes matérias relativas à educação, como oferta, manutenção e desenvolvimento do ensino, gratuidade, obrigatoriedade, vinculação de recursos, ensino religioso entre outros, são temas recorrentes em todos os processos constituintes fornecendo a substância a ser disputada e ordenada pelas forças políticas em cada momento histórico.

Mas, mesmo considerando os avanços e retrocessos próprios de processos de disputas, é fato que, se a educação é matéria que inicialmente se estabelece de forma tímida, concebida originariamente na Constituição de 1824, como "instrução primária gratuita e aberta a todos os cidadãos"3 (BRASIL, 1824), na Constituição de 1988 é declarada, entre outras providências, como sendo "direito de todos e dever do Estado e da família..." (BRASIL, 1988), sendo a implementação de sua oferta e efetivação imposta como dever do Estado. Este direito é ampliado quando esta carta declara que "o acesso ao ensino obrigatório é direito público subjetivo" e que a oferta gratuita deverá ser assegurada a todos, inclusive "para todos os que a ele não tiveram acesso na idade própria" . A educação sai de uma possibilidade aberta a todos em 1824 para a impossibilidade de se alienar desse direito em 1988. Nesse percurso, a educação foi matéria debatida, negociada, disputada e barganhada em todos os processos constituintes pelas lideranças políticas em cada momento histórico ${ }^{7}$. A bem da verdade, foi preciso mais de um século e meio de lutas para a educação constituir-se de fato em um direito social.

Paralelamente ao processo de ordenação da educação como direito social, concorre o processo de ampliação da presença do Estado nas funções educacionais no intuito de garanti-lo, mediante a oferta gratuita a todos os

\footnotetext{
3 Art. 179 da Constituição de 1824.

4 Art. 205 da Constituição de 1988.

5 Art. 208, inciso VII, § $1^{\circ}$ da Constituição Federal de 1988.

6 Art. 208 da Constituição de 1988.

7 Para maiores detalhes ver obra de Fávero (2001) "A educação nas constituintes brasileiras: 1823/1988".
} 
brasileiros, chegando aos dias de hoje com caráter oficial e de incumbência predominante do Estado. Isto porque em uma sociedade marcada por profundas desigualdades sociais, um direito social como o estabelecido para a educação não pode ser obtido na esfera privada dos indivíduos.

Assim, o Estado é tratado aqui como responsável incontroverso pelo provimento da educação como direito público a todos os brasileiros. Ainda que a educação também seja dever da família (BRASIL, 1996 art. $2^{\circ}$ ), isto não exime o Estado do dever de educar e garantir as condições de qualidade para o ensino e a aprendizagem.

Embora a educação como um direito público tenha proteção jurídica declarada, não parece ser condição suficiente para a sua materialização, não obstante possibilite remeter ao Estado a incumbência de torná-la factível. Assim, a presença do Estado na educação não pode ser apenas de caráter supletivo ou subsidiário, mas se configura como obrigação intransferível mesmo que partilhada com a família. Espera-se, então, que os efeitos produzidos socialmente pelas políticas educacionais tendam a assegurar sucessivamente graus elevados da aquisição deste bem social, pois é das ações e prescrições administrativas, provenientes de políticas educacionais ou de sua contestação, que decorre a realização ou não do direito determinado juridicamente.

Assim, a mencionada instituição do Ensino Fundamental como direito público subjetivo inaugura uma intencionalidade que será letra morta caso não se movimentem formas para implementá-la e, portanto, as políticas educacionais podem ser entendidas como a direção dada e este movimento. A sua realização por meio de ações e prescrições pode ser definida como a política em ação, que será tanto mais capaz de promover o acesso ao Ensino Fundamental, como descrito aqui, quanto mais próximas estiverem da intencionalidade prevista. Mas qualquer uma dessas instâncias, seja a constituição jurídica, seja a formulação de políticas de implementação ou as proposições de ações e prescrições governamentais, constitui-se em campo político, ou seja, espaço de disputa e ordenação que nem sempre é referenciada pela distribuição do direito ao Ensino Fundamental.

Mas, quando as ações e prescrições governamentais são pautadas por políticas de implementação de direitos, podem ser entendidas como a forma de distribuição de um determinado bem social. Nesse sentido, 
a distribuição constitui uma característica essencial e distintiva no conceito de justiça. Portanto, justiça tem a ver com a maneira segundo a qual benefícios e encargos, ganhos e perdas são distribuídos entre os membros de uma sociedade, como o resultado do funcionamento de suas instituições: sistemas de propriedade, organizações públicas, etc. (FIGUEIREDO, 1997, p.74).

Ou seja, distribuir justamente um direito ou bem social pode acarretar em distribuições desiguais entre indivíduos ou grupos de indivíduos, pois as necessidades não são as mesmas para todos. Uma distribuição justa seria aquela que concede a cada um o que é necessário para si.

Entretanto, se a ordenação jurídica dos direitos sociais deriva de permanente disputa política, as formas de viabilização ou de distribuição são igualmente frutos de concorrências semelhantes. Emúltimainstância, pesa sobre as formas consubstanciadas como portadoras de suposta efetivação de determinado direito social, um particular entendimento de que são estas e não outras as formas com potencialidade de levar a efeito o referido direito, e isso pode não corresponder ao acesso real daquele direito.

É por essa razão que o reconhecimento, inclusive jurídico, da responsabilidade do Estado na garantia do direito à educação não resulta na sua imediata execução e distribuição, pois estas são arquitetadas no campo político e oferecidas à sociedade, e a distância que esta mantiver da produção das políticas sociais condicionará a maior ou menor possibilidade de equívocos nas escolhas destes produtos.

Por isso depende de como os representantes do campo social que atuam no campo político concebem formas de efetivar políticas educacionais, sustentadas por interesses nem sempre correspondentes aos interesses reais de seus representados, que, não raras vezes, desconhecem a dimensão real de suas próprias necessidades. Daí porque considerar uma distribuição socialmente justa requer considerar demandas nem sempre reivindicadas explicitamente.

Particularizando essas considerações para o Ensino Fundamental, resulta que as condições para o pleno acesso a este direito, além de um assento na escola, requerem que o sujeito acesse igualmente uma aquisição qualificada, com vistas à emancipação social. É essa a idéia de direito à educação compreendida aqui, ou seja, direito a um ensino de qualidade tal que permita ou proporcione 
condições reais de apoderamento de conhecimentos socialmente relevantes, que geram o esclarecimento necessário que mobiliza sujeitos em direção à atuação autônoma e consciente.

Ocorre que, como já mencionado, nem sempre as ações daqueles que operam no campo político são referenciadas por tal acepção do direito à educação e as políticas e ações para sua distribuição entre os cidadãos podem resultar inócuas.

Nesse sentido, interessa saber o que move indivíduos ou grupos de indivíduos a disputarem o direito de estabelecer diretrizes acreditando ou declarando serem estas as que fornecem os recursos para a obtenção de um direito socialmente reconhecido e almejado pela sociedade, no caso específico, no direito de estabelecer políticas e ações educacionais.

A razão da permanente marca de disputa que perpassa todo campo político na busca do monopólio do poder está no sentido que move as ações dos indivíduos. Para Weber (2004), o sentido que orienta uma ação política é, via de regra, racional referente a fins, isto é, a razão que leva um indivíduo a agir de uma determinada forma no campo da política, ou a racionalidade que orienta sua ação está na determinação de um sentido que é essencial e pragmaticamente focado nos fins, ainda que seja impossível determinar o limite da ação pragmática na política, uma vez que sempre há algum grau de orientação baseada nos valores próprios do sujeito que atua na política.

Quando a orientação ou sentido da ação de um indivíduo é referenciada pelas ações de outros indivíduos, ela é considerada uma ação social. Quando há reciprocidade nas referências de uma ação social, ou seja, quando as ações dos indivíduos são orientadas mutuamente, o autor diz ser uma relação social. Dessa forma, pode-se pensar o Estado como uma construção social, resultado das ações sociais dos indivíduos, que são movidos por diferentes sentidos e que agem de acordo com fins ou valores. A reciprocidade do conteúdo do sentido das suas ações faz desses indivíduos um agrupamento. Assim, política é a direção que toma determinado agrupamento político ou a sua influência em um determinado sentido. Para o autor, então, o Estado é uma relação de dominação, fundada na obediência legitimada ${ }^{8}$, ou seja, nas razões que fazem com que alguns tenham o

8 As fontes de legitimação da dominação residem basicamente na tradição, no carisma e no estatuto legal. Sobre as fontes de legitimação de poder, ver mais em Weber (2004). 
poder de mando e outros o dever da obediência, e que condiciona ou influencia o sentido de uma determinada ação governamental (WEBER, 2004).

As determinações decorrentes do campo político, especialmente em relação às políticas educacionais, são frutos das relações de dominação que movem as ações dos agrupamentos políticos para uma determinada direção ou sentido, mesmo que os resultados da política não sejam expressão única da vontade do governante, uma vez que sempre o produto da política é o amálgama entre o sentido apontado pelo dominador e a (possível) resistência dos dominados. Esta direção, ou sentido, produz políticas educacionais com características próprias, por isso, na medida em que muda a direção ou influência mudam também as características das políticas educacionais. Não são raras as dissonâncias entre formulação, ordenação e execução de uma política educacional, pois os agrupamentos políticos que dão o sentido em uma e outra dessas instâncias podem não ser os mesmos e, por isso, lutam para tomar parte do poder. Ou seja, a política é o esforço realizado com vistas a participar do poder, no intuito de influenciar a sua divisão, conservação ou transferência. É este o sentido que move o Estado como agrupamento político (WEBER, 2004).

Se as políticas educacionais resultam da disputa entre forças que atuam no campo político e tais forças assim fazem-no referenciadas pelas ações de outras forças, ou de outros grupos no interior do campo, é verdade também que os agrupamentos que disputam o poder e organizam as políticas o fazem referenciadas pelas ações externas, dos possíveis usuários destas políticas, pois a garantia de permanência dos sujeitos que vivem na/da política (WEBER, 1968) reside, em grande parte, na capacidade de serem aceitos como representantes legítimos de determinados grupos sociais, o que os levam a falar e agir em nome destes (BOURDIEU, 2004). O reconhecimento da autoridade legítima desta representação pode garantir que as normatizações com vistas à execução daquelas políticas de fato passem de propósito para política em ação no campo das políticas educacionais (BOURDIEU, 2004; WEBER, 2004).

É amparada na idéia de que as políticas educacionais, assim como as correspondentes regulações jurídicas, são resultados da disputa que permeia o campo político, sendo o Estado, como construção social, o portador dessas políticas com a responsabilidade de torná-las factíveis, que essa análise busca enfatizar alguns dos efeitos das políticas educacionais onde elas se efetivam, 
consideradas como o resultado de ações referenciadas pelo intuito de permanecer no poder ou com a intenção de distribuir um benefício socialmente aceito.

Por outro lado, interessa também discutir em quais condições se pode aceitar que o direito à educação é disponibilizado aos cidadãos, pois a modelagem deste direito é igualmente disputada no campo político. O debate acerca do que de fato faz com que este direito seja atendido, embora ainda não consensual, há muito já superou a idéia do acesso ao direito pela garantia da matrícula. As discussões no contexto atual, mesmo que em diferentes medidas, tangenciam a aquisição escolar como forma de acesso ao direito à educação, ou seja, direito à educação é direito a aprender ou, de acordo com a definição da UNESCO (2005), direito à aquisição cognitiva. Entretanto, não se pode aceitar qualquer aquisição como distribuição deste direito, ou seja, a aquisição escolar aceitável é aquela que possibilita a emancipação de todos os cidadãos de forma qualificada e equitativa.

Assim, faz todo sentido monitorar políticas, ações e prescrições governamentais com intuito de avaliar o quão efetivas são em relação à distribuição do direito na modelagem assim definida.

Nessa medida, o que estudantes aprendem na escola é um dos instrumentos que devem compor os sistemas de controle de políticas educacionais, no sentido de ampliar as esferas de responsabilização pela disponibilização do direito à educação para todos. Por isso, exames padronizados podem, em certa medida e aliados a outros instrumentos, revelar o grau de efetividade da ação governamental na área educacional.

Portanto, o estudo aqui desenvolvido está ancorado no entendimento que a produção e viabilização de políticas educacionais são produtos disputados no campo político e influenciam ações educativas executadas no interior das escolas e consequentemente têm uma parcela de explicação nos resultados da aquisição escolar.

\section{Ação governamental e resultados estudantis para - Ensino Fundamental no município de Curitiba.}

O Ensino Fundamental integra, juntamente com a Educação Infantil e o Ensino Médio, as três etapas da Educação Básica Nacional. Embora a Educação 
Básica seja reconhecida como direito de todos os brasileiros, somente o Ensino Fundamental é marcado pela legislação como obrigatório9.

Assim, esta etapa da Educação Básica constitui-se escolarização obrigatória a todos os brasileiros cuja extensão, alterada pela Lei n. ${ }^{\circ} 11.274 / 06$, é fixada em nove anos, com matrícula obrigatória aos seis anos de idade.

A organização do Ensino Fundamental, embora convencionada legalmente como uma única etapa, constitui-se de fato na justaposição de duas partes distintas, particularmente organizadas, denominadas anos iniciais (cinco anos de duração) e anos finais (quatro anos de duração).

Após quase quatro décadas de junção, a percepção de uma justaposição ainda hoje persiste e é revelada nas formas de organização diferenciadas para cada parte do Ensino Fundamental que, de tão díspares, a menção a esta etapa da Educação Básica se dá de forma recorrente com a necessária especificação das partes que a compõem, ou seja, anos iniciais (AI) e anos finais $(\mathrm{AF})^{10}$. A organização pedagógica para uma e outra parte difere substancialmente seja nas exigências de formação docente, seja na organização dos saberes, nas metodologias utilizadas, para não falar na organização estrutural, que nem de longe se mostra sequencial ou contínua. Pode-se dizer que o máximo conseguido foi justapor dois cursos distintos, o "primário" e o "ginásio", ampliando a oferta obrigatória.

Este fato pode estar relacionado com as formas encontradas pelos Estados e municípios para sua oferta e atendimento, normalmente com a repartição das referidas partes, $\mathrm{AI}$ e AF, entre as esferas de governo, ficando predominantemente aquela sob a tutela dos municípios e esta sob o comando dos governos estaduais ${ }^{11}$.

Ocorre que se as exigências são específicas, também as intervenções devem ser particularizadas para cada parte do Ensino Fundamental, exigindo das redes de ensino, planejamentos próprios e adequados às suas responsabilidades. No entanto, há casos em que redes de ensino que ofertam o Ensino Fundamental

9 Pelo menos até 2016, quando, conforme estabelece a Emenda Constitucional 59/2009, a obrigatoriedade será estendida para todas as crianças e adolescentes entre os 4 e os 17 anos de idade.

10 Tal nomenclatura varia no país: séries iniciais e séries finais; primeiro segmento e segundo segmento, etc.

11 Ainda está por ser realizado estudo mais atualizado sobre os diferentes arranjos do regime de colaboração entre estados e municípios na oferta do ensino fundamental. Mas, a constituição da política de fundos (FUNDEF e, depois, FUNDEB) parecem ter induzido um modelo mais próximo ao indicado no texto. 
completo tentam adaptar, ou simplesmente estender para toda a etapa, ações formuladas para uma das partes, priorizando, assim, uma das partes do Ensino Fundamental. Ao priorizar o atendimento a uma das partes, termina por secundarizar a outra, fato bastante preocupante ao tratar-se do direito ao Ensino Fundamental, quando alunos poderiam não estar sendo beneficiados pela ação pública com vistas à aquisição dos conhecimentos.

A oferta e o atendimento do Ensino Fundamental no município de Curitiba até o momento são organizados nos moldes de uma particular forma de repartição em que as redes estadual e municipal se responsabilizam por uma parte prioritariamente e outra parte é atendida de forma não prioritária, mas presente, mesmo que minimamente em cada rede. Por isto, há a rede municipal atende prioritariamente escolas dos $\mathrm{AI}$, mas também possui escolas com oferta dos $\mathrm{AF}$ e, de outro lado, a rede estadual do Paraná, atende predominantemente os AF, mas também oferta escolas dos AI, as quais, por sinal, formam um conjunto não tão pequeno de escolas com atendimento precário no município de Curitiba.

Presume-se que o acordo ${ }^{12}$ que define a divisão de responsabilidades entre as esferas de governo no município de Curitiba na oferta e atendimento do Ensino Fundamental, resulte em prescrições e ações governamentais correspondentes para cada parte desta etapa da Educação Básica advindas da rede de ensino responsabilizada pela sua manutenção. Ocorre que, como mencionado, apesar do acordo, as duas redes mantêm escolas que ofertam as duas partes do Ensino Fundamental, porém, priorizando uma delas, situação esta que reclama de cada rede ações distintas para cada parte do Ensino Fundamental. No entanto, não é isso que parece ocorrer. No caso da rede municipal, as políticas educacionais são prioritariamente direcionadas à Educação Infantil e aos AI do Ensino Fundamental, pois esta é a parte, procedente daquela divisão, sob seu encargo. Para a rede estadual coube o atendimento dos AF do Ensino Fundamental e Ensino Médio e é onde incide a priorização de políticas governamentais. Todavia, nas duas redes parece não haver uma política específica para cada parte do Ensino Fundamental. Isso não significa, porém, a possibilidade de assumi-lo como um bloco articulado, mas, quando muito, uma tendência a tomar as políticas específicas propostas para a parte prioritária, como convenientes para ambas as partes.

12 A municipalização do ensino no estado do Paraná remonta aos anos 1980. Todavia, em algumas cidades, e Curitiba é a principal delas, este procedimento não foi plenamente efetivado, havendo a participação das redes municipal e estadual na oferta de ambas as partes do ensino fundamental. 
A ideia de que os investimentos políticos são mais intensos e regulares onde determinada esfera de governo tem a responsabilidade de oferta e atendimento, pressupõe que poderia haver diferença nos resultados estudantis entre uma parte e outra do Ensino Fundamental, já que em Curitiba a partilha da oferta assume aspecto peculiar.

A análise dos resultados estudantis das escolas públicas da cidade a partir das informações decorrentes das aferições do Índice de Desenvolvimento da Educação Básica - Ideb $^{13}$, mostra que é possível levantar algumas considerações importantes ${ }^{14}$.

Para isso, as escolas foram organizadas em grupos, de acordo com os resultados obtidos nas duas aferições do Ideb. Foram consideradas escolas com bons resultados (EBR), as $25 \%$ com os resultados médios mais altos; escolas com resultados preocupantes (ERP), as $25 \%$ com os resultados mais baixos e escolas intermediárias (EI), aquelas situadas entre os dois primeiros grupos, que perfazem o conjunto de $50 \%$ das escolas. Esse agrupamento foi realizado para cada parte do Ensino Fundamental separadamente e comparadas em cada rede de ensino, estadual e municipal.

As informações obtidas mostram que onde a ação governamental é mais intensa e regular, o conjunto de escolas tende a se apresentar mais homogêneo. Ou melhor, ao comparar os resultados obtidos nas duas redes de ensino na mesma parte do Ensino Fundamental, nota-se que os resultados variam menos, isto é, são mais parecidos onde são considerados como atendimento prioritário (os anos iniciais na rede municipal e os anos finais na rede estadual). De forma análoga, quando se compara os resultados nas duas redes da parte do Ensino Fundamental de atendimento não prioritário, os resultados se mostram mais heterogêneos, isto é, o conjunto de escolas nesta situação apresenta maior variabilidade nos resultados. Além da homogeneidade presente nos grupos prioritários de cada rede, quando são comparados os resultados estudantis entre uma aferição e outra, percebese uma tendência de elevação, ou um movimento ascendente, neste

13 Ideb: indicador de qualidade educacional que combina informações de desempenho em exames padronizados do Saeb e da Prova Brasil - obtido pelos estudantes ao final das etapas de ensino $\left(4^{\mathrm{a}}\right.$ e $8^{\mathrm{a}}$ séries $/ 5^{\circ}$ e $9^{\circ}$ anos do Ensino Fundamental) - com informações sobre aprovação escolar.

14 Foram analisados os dados do IDEB para todas as escolas públicas do ensino fundamental de Curitiba, tanto da rede municipal quanto da rede estadual de ensino. 
conjunto de escolas, diferente do grupo não prioritário, que demonstra uma instabilidade maior do conjunto de seus resultados.

Na Tabela 1, os dados se referem às escolas que ofertam os AI em Curitiba. Nota-se que, neste caso, a prioridade de atendimento é reservada à rede municipal que oferta e mantém perto de $80 \%$ do conjunto de escolas da cidade, enquanto a rede estadual mantém as outras aproximadamente $20 \%$ de escolas que ofertam os AI. As escolas da rede municipal concentram seus resultados no grupo de escolas EI, (próximo de $50 \%$ de suas escolas) enquanto as escolas da rede estadual se distribuem em todos os grupos. Esta característica se mantém entre uma aferição e outra do indicador com uma importante peculiaridade. As escolas da rede estadual, embora mantenham a característica heterogênea em 2007, apresentaram um movimento de queda entre os grupos, ou seja, o percentual de escolas EBR diminui junto com o incremento no percentual de escolas EI e ERP desta rede, deslocandose de forma descendente entre os grupos. Esta característica é ainda mais acentuada em 2009 e, ainda que em 2011 note-se alteração no movimento, o maior percentual de escolas desta rede estão no grupo ERP, posição inversa à observada no inicio do período observado.

Já as escolas municipais, apresentam um movimento inverso, os percentuais deslocam-se ascendentemente, apresentando em 2007 e 2009 um incremento nas escolas EBR e uma diminuição do percentual de escolas no grupo ERP. Em 2011, nota-se também uma alteração no movimento e observa-se um incremento no percentual de escolas no grupo ERP, e um arrefecimento do percentual de escolas no grupo EBR, porém ainda que se observe esta inflexão, o maior percentual de escolas da rede municipal continua classificado como EI, ou seja, há mais escolas com resultados intermediários mantendo a homogeneidade observada em 2005 durante todo o período observado. É como se o conjunto de escolas municipais, nesta parte do Ensino Fundamental, fosse içado enquanto o conjunto das escolas estaduais, nessa condição, tende a um movimento inverso. Isto pode ser melhor visualizado nas informações contidas nos retângulos sombreados da Tabela 1. 
Tabela 1 - Grupos de escolas AI segundo a variação do ideb por dependência administrativa

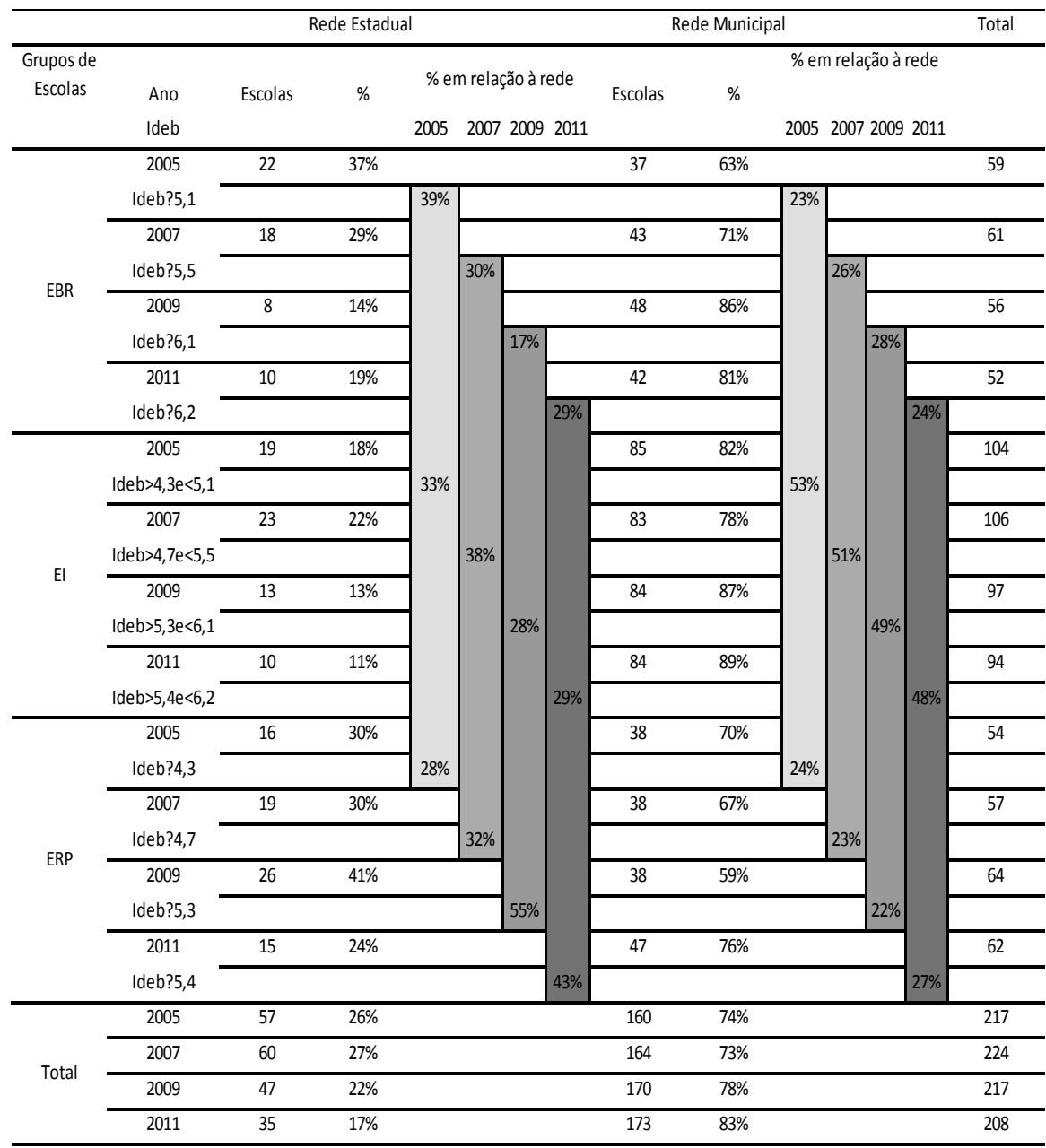

Fonte: MINISTÉRIO DA EDUCAÇÃO (2005, 2007, 2009 e 2011).

Legenda: $\mathrm{EBR}=$ Escolas com Bons Resultados; $\mathrm{EI}=$ Escolas Intermediárias: $\mathrm{ERP}=$ Escolas com Resultados Preocupantes.

Movimento similar pode ser observado em relação aos anos finais, todavia, de forma inversa no que tange a quem (qual rede de ensino) cabe o atendimento prioritário dessa parte do Ensino Fundamental. A rede estadual atende aproximadamente $93 \%$ destas escolas, enquanto apenas $7 \%$ estão sob a manutenção da rede municipal. Ainda que para este grupo de escolas dos 
anos finais o grau de homogeneidade seja menos intenso quando comparados com os resultados dos AI, agora é na rede estadual que as escolas tendem a resultados intermediários mantendo esta característica em todas as aferições, ou seja, se apresenta, tendencialmente, mais homogênea. Contudo, para esta parte do Ensino Fundamental, os valores do IDEB que determinam os limites de cada grupo de escolas não sofrem alterações nas aferições a partir de 2007. Isso pode indicar certa estagnação no movimento dos resultados do indicador, que pode estar relacionada com a dificuldade da política educacional em propor ações mais efetivas para os anos finais, diferente do constatado para os anos iniciais. Mas, ainda que se constate o maior percentual de escolas EI, igualmente nota-se que, em todas as aferições, o percentual de escolas ERP é superior em relação às escolas EBR. Neste caso, parece que a homogeneização está localizada nos grupos de escolas, EI e ERP; ainda assim, o movimento é regular.

Quanto ao conjunto de escolas AF municipais, que numa primeira análise pode-se considerar a possibilidade do ser mais homogêneo, dado que, em $2007,55 \%$ destas escolas situam-se no grupo EI, percebe-se claramente que o movimento do conjunto foi descendente. Percebe-se que na rede municipal o conjunto de escolas AF apresenta, em 2005, uma grande concentração no grupo EBR (67\%), em 2007, apresenta uma inversão nos percentuais, passando a concentrar seus resultados nas escolas EI (55\%), deslocando o conjunto de suas escolas a patamares de comparação inferiores ao observado em 2005, não preservando a uniformidade do desempenho. Nas aferições posteriores, a maior incidência de escolas entre os grupos oscila entre o grupo EBR e EI, gerando instabilidade no movimento do conjunto de escolas, ainda que se considere que nas aferições de 2009 e 2011, tais escolas não tenham representação no grupo de escolas ERP. Também importa ressaltar que o conjunto de escolas AF da rede municipal, ainda que reduzido, mantém-se inalterado no período observado. Estas informações estão sintetizadas na Tabela 2, onde podem ser observados estes movimentos, especialmente nos retângulos sombreados. 
Tabela 2 - Grupos de escolas AF segundo a variação do ideb por dependência administrativa

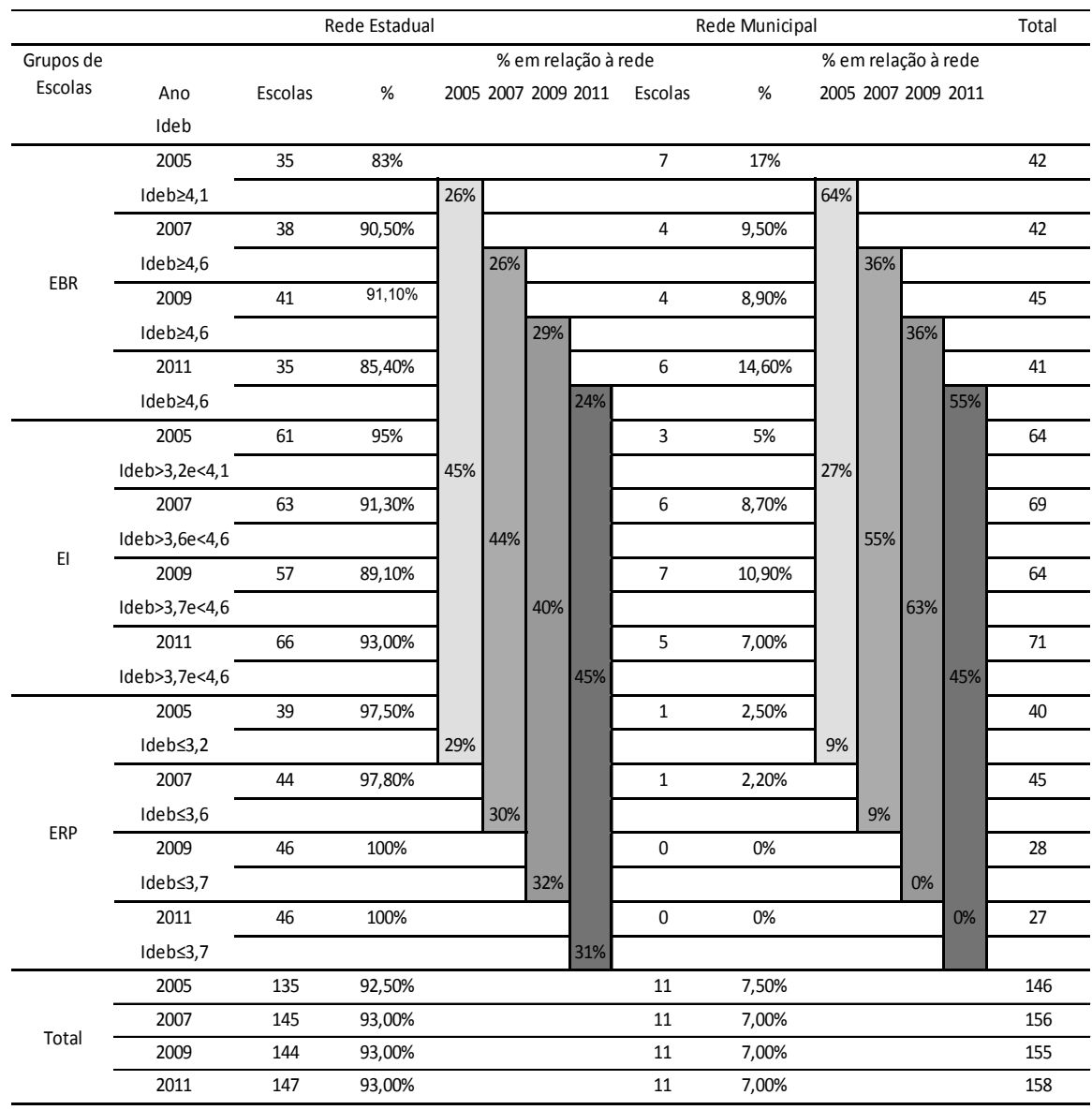

Fonte: MINISTÉRIO DA EDUCAÇÃO (2005, 2007, 2009 e 2011).

Legenda: $\mathrm{EBR}$ = Escolas com Bons Resultados; $\mathrm{EI}$ = Escolas Intermediárias: $\mathrm{ERP}=$ Escolas com Resultados Preocupantes.

Coincidentemente, nas duas redes os resultados estudantis adquirem um caráter mais homogêneo acompanhado de um movimento em direção a resultados melhores para o conjunto de escolas da parte prioritária, na qual os investimentos públicos parecem ser mais intensos ou mais objetivamente direcionados.

Por isso, não parece ser o fato de pertencer a uma ou outra rede que influencia os resultados, mas a intensidade e o volume das prescrições governamentais 
na etapa prioritária de cada rede, pois o inverso também se confirma: onde as redes não têm oferta prioritária, os AI para a rede estadual e os AF para a rede municipal, destaca-se um grau de heterogeneidade e uma tendência a não uniformidade dos resultados.

A considerar os dados apresentados, pode-se inferir que a intensidade e a regularidade das prescrições governamentais tendem a produzir resultados estudantis mais homogêneos, ou seja, uma rede homogênea tem o mérito de alcançar de forma mais equânime uma esfera mais ampliada, ainda que com níveis de qualidade aquém do desejado. Isto é possível, na medida em que, neste caso, as formas de controle também são mais intensas e regulares, e a política está sob maior cobrança e atenção pública. De igual maneira, a irregularidade ou a ausência de prescrições governamentais tende a produzir resultados mais heterogêneos, fazendo com que o acesso à aquisição de conhecimentos para os alunos dessas escolas seja derivado de ações menos controladas pela política educacional e, por isto, mais dependente de outros fatores.

Entretanto, a homogeneização com vistas à aquisição qualificada para todos não pode se mostrar estacionária, mas em movimento ascendente. Dessa forma, é a direção (ascendente ou descendente) da homogeneização que pode medir o quanto uma política pode ser considerada efetiva na equalização de percursos escolares com vistas à emancipação social. Por isso, espera-se que sistemas de ensino direcionem políticas educacionais que produzam resultados estudantis cada vez melhores para todos os estudantes. Este é o critério para monitorar o acesso ao direito à educação a todos os cidadãos.

No caso da oferta e manutenção do Ensino Fundamental em Curitiba, a investigação revelou que a confirmação de políticas mais intensas na parte de atendimento prioritário pode ser associada a uma menor variabilidade dos resultados estudantis. Isto é, há similaridade no movimento dos resultados dos alunos dos AI na rede municipal e alunos dos AF da rede estadual, ambos considerados prioritários nas redes de ensino às quais pertencem. Além de os estudantes apresentarem resultados mais próximos, também se movimentam em conjunto em direção a resultados melhores, na condição assinalada anteriormente. O que quer dizer que a ação do Estado, quando organizada, apresenta resultados positivos no que tange a esta dimensão do direito à educação. 
Por outro lado, a ausência, a irregularidade ou a não objetividade da ação governamental também constatada nas partes não prioritárias das redes de ensino podem ser associadas a uma maior variabilidade no conjunto dos resultados das escolas nesta condição, ou seja, escolas AF da rede municipal e escolas AI da rede estadual. Estes dois grupos de escolas mostram igual instabilidade no movimento dos resultados, ora tendendo a pontuações mais altas, ora caminhando para resultados mais preocupantes, caracterizando conjuntos mais heterogêneos, numa clara demonstração de que outros fatores podem estar interferindo mais do que a ação governamental nos resultados educacionais. Dessa forma, políticas educacionais de atuação fraca abrem ou ampliam espaço à influência de fatores como condição socioeconômica, cultural, étnica, entre outros, na produção e reprodução das desigualdades sociais.

Assim, a ação do Estado pode atuar como um freio na produção das desigualdades sociais e um acelerador na distribuição de direitos sociais, no caso, o direito à educação. Isso quer dizer que parece não ser possível pensar na justa distribuição do direito à educação na ausência de políticas de Estado.

\section{Conclusões}

A análise dos dados da pesquisa mostrou que admitir a priorização do atendimento a uma das partes do Ensino Fundamental significa secundarizar a outra parte, dada a especificidade exigida na organização de cada uma delas. No caso de Curitiba, o critério utilizado na divisão de responsabilidades são as partes do Ensino Fundamental, ou AI e AF. Isso é preocupante, porque, na verdade, o que se reparte são os estudantes e, como é uma divisão que não ocorre de forma plena, parte deles fica com atendimento secundarizado, ou seja, o benefício deste direito pode não estar sendo disponibilizado adequadamente a todos os estudantes de Curitiba.

Assim, a análise das informações revelou que a ação governamental é decisiva na distribuição do direito à educação, pois tem a função de equalizar trajetórias educacionais de todos. Isto é de fundamental importância num contexto de desigualdades sociais, onde o acesso ao direito não ocorre na esfera individual, mas na presença do Estado, que é o responsável incontroverso pela sua distribuição equânime. 
Por isso, os processos educacionais precisam ser monitorados pela sociedade, pois é necessário garantir o sentido e a direção de suas trajetórias, com a responsabilização de todas as esferas envolvidas, especialmente a esfera governamental.

É desejável que ações intensas e regulares atinjam todos os estudantes de uma determinada rede de ensino. Nesse sentido, esforços precisam ser somados, responsabilidades precisam ser divididas para que o Ensino Fundamental seja distribuído a todos os cidadãos, e isso é lícito e necessário. Também é verdade que a modelagem do acordo que normatiza a partilha da oferta educacional resulta em priorizações de responsabilidades para cada esfera de governo, e também o problema não reside neste fato. Pode-se priorizar, dividir e repartir todas as responsabilidades sobre os meios necessários ao pleno atendimento, o que não pode ser segmentado são os estudantes. Todos eles devem ser atingidos por políticas educacionais intensas, constantes e profícuas, todos devem ser prioritários, com plenitude do atendimento de qualidade. Esta é uma questão que precisa entrar na pauta de discussão das duas esferas de governo do município de Curitiba e da sociedade em geral se o objetivo é o direito à aquisição de conhecimentos como direito à educação para todos.

\section{Referências}

BOURDIEU, P. O Poder simbólico. Rio de Janeiro: Bertrand Brasil, 2004.

BRASIL. Constituicão (1824). Constituição Politíca do Imperio do Brazil de 25 de março de 1824. Brasília, DF, 1824. Disponível em: <http://www. planalto.gov.br/ccivil_03/constituicao/constitui\%C3\%A7ao24.htm>. Acesso em: 15 jan. 2014.

. Constituição (1988). Constituição da República Federativa do Brasil de 1988. Brasília, DF, 1988. Disponível em: <https//www.planalto.gov.br/ ccivil_03/Constituicao/Constitui\%C3\%A7ao.htm>. Acesso em: 15 jan. 2014.

. Lei $\mathrm{n}^{\circ} 5.692$ de 11 de agosto de 1971. Fixa Diretrizes e Bases para o ensino de $1^{\circ}$ e $2^{\circ}$ graus, e dá outras providências. Diário Oficial da União, Brasília, DF, 12 ago. 1971. Disponível em: <http://www010.dataprev.gov.br/ sislex/paginas/42/1971/5692.htm>. Acesso: 15 jan. 2014. 
BRASIL. Lei no 9.394 de 20 de dezembro de 1996. Estabelece as diretrizes e bases da educação nacional. Diário Oficial da União, Brasília, DF, 23 dez. 1996. Disponível em: < http://www.planalto.gov.br/ccivil_03/leis/19394.htm>. Acesso em: 15 jan. 2014.

FÁVERO, O. (Org.). A educação nas constituintes brasileiras: 1823-1988. Campinas: Autores Associados. 2001.

FIGUEIREDO, A. Princípios de justiça e avaliação de políticas. Lua Nova: Revista de Cultura e Política, [S.1], n. 39, 1997.

MINISTÉRIO DA EDUCAÇÃO. Microdados Prova Brasil 2005. Brasília, DF: Inep, 2005. Disponível em:<www.inep.gov.br>. Acesso em: 15 jan. 2014.

. Microdados Prova Brasil 2007. Brasília, DF: Inep, 2007. Disponível em:<www.inep.gov.br>. Acesso em: 15 jan. 2014.

. Microdados Prova Brasil 2009. Brasília, DF: Inep, 2009. Disponível em: $<$ www.inep.gov.br>. Acesso em: 15 jan. 2014.

. Microdados Prova Brasil 2011. Brasília, DF: Inep, 2011. Disponível em:<www.inep.gov.br>. Acesso em: 15 jan. 2014.

UNESCO. Organização das Nações Unidas. Relatório de Monitoramento Global - 2005: Educação Para Todos.Brasília, DF: UNESCO, 2005. Disponível em: <http://www.brasilia.unesco>. Acesso em: 15 jul. 2008.

WEBER, M. Economia y sociedad. México: FCC, 2004. . Ciência e Política: duas vocações. São Paulo: Cultrix, 1968. 


\section{The right to primary education through the reading of the results of IDEB and educational policy in Curitiba-PR - Brazil}

\section{Abstract}

The article discusses the State role in guaranteeing the right to education based on the conciliation between government actions and IDEB results in public primary schools. After presenting the basis in which the theoretically analysis operates, especially Weber and Bourdieu, the paper presents and discusses the (non) prioritization to primary education from the data of IDEB. The findings show that the basic education (early or final grades) prioritized by the government tends to provide more homogeneous results, meaning with this some expansion of the right to education. On the other hand, when the government does not prioritize certain part of basic education, heterogeneity seems to dominate, leaving the students who are forced into this position more dependent of other variables to have their right to education guaranteed.

Keywords: Right to education. Primary education. Educational Policy. IDEB.

\section{El derecho a la enseñanza fundamental en una lectura de los resultados del IDEB y de la política educacional en Curitiba-PR - Brasil}

\section{Resumen}

El artículo aborda el papel del Estado en el ítem de garantizar el derecho a la educación a partir del cotejo entre las acciones gubernamentales y los resultados del IDEB (Índice de la Educación Básica) de las escuelas públicas de la enseñanza fundamental. Después de presentar las bases teóricas del análisis, especialmente Weber y Bourdieu, el texto presenta y discute la (no) prioridad a la educación primaria a partir de los datos del IDEB. Los resultados muestran que la etapa de educación básica (años iniciales o finales) priorizada por el gobierno tiende a proporcionar resultados más homogéneos y crecientes, lo que significa ensanchamiento del derecho a la educación. Por otra parte, cuando el gobierno no da esa prioridad a cierta parte de la educación básica, la heterogeneidad parece dominar, lo que deja a los estudiantes que están en estas condiciones más dependientes de otras variables para garantizar su derecho a la educación. Palabras-clave: Derecho a la educación. Enseñanza fundamental. Políticas Educacionales. IDEB. 